\title{
Raúl Dorra
}

\section{Los relatos literarios: entre la proliferación y la clasificación (ensayo de un esquema ternario)}

1. ¿Es posible conocer un tipo discursivo sin dar atención al cuadro que lo contiene? ¿Es posible, por ejemplo, hablar propiamente de una especie de relatos sin haber indagado en el género que le da sentido como tal, simplemente dejando que ese género permanezca en la conciencia como un fondo, o en todo caso como un universo difuso? Preguntas de esta naturaleza, que implican de entrada una toma de partido por la abstracción, nos encuentran siempre dispuestos a una respuesta negadora pero una práctica tensa $\rightarrow$ que, al mismo tiempo, con el mismo afán de rigor es necesario asumir pues al cabo es la que da forma a la conciencia colectiva- - nos indica que debemos ser más cautelosos en esta apelación a la lógica. Así, una vez más, la reflexión que se quiere completa debe ser un compromiso entre la abstracción y la experiencia. Para el caso del estudio de los relatos literarios, el crítico no puede dejar de lado esa conciencia, pues en gran parte la literatura es un efecto de ella, como tampoco debe renunciar a la búsqueda de un método que lo lleve, incluso a veces en contra de esa conciencia, a trazar mapas y territorios para su propia comprensión, a definir y contrastar, en suma: a operar clasificaciones.

¿Qué son los relatos literarios y cómo pueden quedar ordenados en un esquema científico que comprenda su vastedad y. que asimismo dé cuenta de las formas que propone una mirada histórica más o menos institucionalizada -es decir: convencional - que es expresión y al propio tiempo fuente de la conciencia literaria colectiva? He aquí una buena oportunidad para la reflexión, al menos para un ejercicio que, 
si no resulta exitoso, no dejará por esto de ser aquello que pretende: una invitación a ocupar de manera más plena un campo de observación del que la crítica parece no haberse instalado sino en una parcela; el campo de observación es en este caso el de los relatos literarios.

Llamo relatos literarios a los enunciados narrativos ordenados en secuencias cuyạ elaboración y cuya recepción asumen la forma de un trabajo artístico. Si se trata de tener en cuenta tanto la elaboración cuanto la recepción del mensaje - "el Espíritu en tanto produce y consume literatura", diría Valéry-para el crítico la clasificación no sera fácil pues deberá tener en cuenta, sin exclusión posible, el haz de factores que contribuyen a la realización de un efecto discursivo como efecto "literario". La literatura, recordémoslo, reúne en un equilibrio precario y móvil -por lo menos- dos elementos heterogéneos y solidarios: la estructura y la historia. La estructura como sistema interno, perdurable, y la historia - la historicidad- como factor variable que pone, cada vez, en acto el sistema. Para que un enunciado verbal sea literario no basta, lo sabemos, que esté estructurado de una determinada manera; hace falta, además, que una mirada viva lo perciba como tal en un momento dado: el ser debe hacerse devenir. $\mathrm{La}$ propuesta de la escritura programada como escritura artística ha de tener realización en una lectura que, de acuerdo con pautas de interpretación sostenidas socialmente, pautas que determinan, en el otro extremo, un "arte de leer", recoge el programa y lo consagra como acontecimiento estético. Esa mirada es la que convierte a la estructura inteligible del mensaje en un objeto sensible, en este caso en materia de contemplación y llamado del deseo.

El órgano de apropiación de la literatura no puede ser, por eso, el intelecto, sino siempre la sensibilidad, un órgano considerablemente más complejo que no excluye al intelecto sino que lo sitúa. ¿Es posible una sensibilidad inteligente, una inteligencia cuya virtud habilitante sea la capacidad de dejarse conducir por la emoción? La crítica literaria debería ser - debe ser- una apuesta en esa dirección. Siendo la sensibilidad un órgano de características difusas - pero no por ello menos capaz de educación y de rigor-el crítico ha de tener en ella su fuente y también su límite: partiendo de esa reunión -siempre 
móvil- de lo inteligible con lo sensible, los juicios y las clasificaciones que de ello resulten tendrán siempre, por lo menos, un aspecto relativo.

Pero la mirada - o la lectura - no puede contentarse con interpretar un texto como literario pues inmediatamente encontrará que el conjunto de tales textos forma un universo demasiado vasto y multiforme; la mirada, además, para comprender necesita organizar el campo, asociar ese texto a una familia más o menos específica y relacionarla con otras, distinguir territorios dentro del mapa. En tanto cada lectura es un acto comprensivo, toda lectura es al mismo tiempo una clasificación: se lee dentro de un género y aun dentro de una especie y aun, si se trata de una mirada especializada, dentro de una subespecie, de una escuela o de un estilo. Si las clasificaciones operadas por esta mirada han de fundarse tanto en la estructura del texto como en las convenciones de interpretación históricamente vigentes, tales clasificaciones, obviamente; tenderán a modificarse con el tiempo ya que cada época tiene una conciencia literaria más o menos diferenciada. Por este motivo, las clasificaciones basadas en datos invariables - digamos en criterios puramente estructurales o inmanentes- si bien son útiles para las necesidades de la teoría, no están en condiciones de dar cuenta del hecho literario en su globalidad. Así, si lo que venimos diciendo es verdadero, para establecer una clasificación debemos preguntarnos de entrada qué distinciones tiende a realizar, en la materia que nos interesa, la conciencia literaria de la que formamos parte, y, enseguida, de qué modo - y hasta qué punto- esas distinciones dan cuenta de la estructura interna de los textos para, finalmente, indagar cómo la convergencia de estos factores organiza el universo de los textos literarios en un cuadro de coherencias, de conflictos o de contradicciones.

2. En los países de lengua española, las convenciones que presiden la lectura - esto es: la conciencia literaria colectiva- tienden de inmediato a reconocer en el universo de los relatos dos grandes familias o especies: el cuento y la novela. La precariedad de esta clasificación, observada científicamente, no ha debilitado sin embargo su eficacia social: ella tiene asegurado, en efecto, un grado de institucionalización suficientemente fuerte como para normar el mundo 
de lo literario. Dicha convención es la que, en general, siguen las revistas especializadas, la crítica profesional, los medios de difusión, las editoriales, los programas de enseñanza: en suma, prácticamente todas las instancias que actúan en la sociedad como autoridad reconocida. En tanto se escribe y se lee desde esa convención, ella tiende a repetirse y perpetuarse como una institución pública. Así, el cuento y la novela, géneros institucionalizados aun en medio de una inconformidad que los especialistas difunden al mismo tiempo que de hecho neutralizan, son promovidos por los organismos que promueven concursos, que distribuyen becas o que programan talleres, lo que supone que aquellas formas narrativas que no alcanzan a agruparse en una u otra familia quedan destinadas a flotar en un espacio incierto, innominado, a la larga adverso. Por ejemplo los talleres literarios -que tanto han proliferado en los últimos años- suelen diversificar y limitar el aprendizaje según esta clasificacion; de ese modo, un joven narrador que no pueda presentarse como aspirante a novelista o cuentista tendrá de hecho dificultado el acceso a los talleres, como también a las becas, las publicaciones y los concursos. Todo ello desde luego implica una continua presión para que este aspirante a narrador se decida, por fin, a convertirse en novelista o cuentista, con lo cual la convención se habrá retroalimentado.

Dejo está últimas observaciones solamente apuntadas pues no es ahora mi interés extraer las consecuencias ideológicas que obviamente se derivan de ellas. Me interesa preguntar: ¿este hábito de tal modo resistente de la conciencia literaria puede ser explicado por razones que no sean puramente sociológicas? Entre el cuento y la novela hay una diferencia simple e inmediatamente perceptible: el primero puede ser leído, y/o analizado, en una unidad temporal limitada - un momento de ocio, una sesión de trabajo-mientras la novela exige un seguimiento fracturado por las interrupciones, diversificado, diferido, pues siempre continúa más allá no sólo de lo que una ociosa libertad suele consentir sino sobre todo de lo que la concentración mental puede soportar. El "ocio atento" que reclamaba Góngora para la lectura de sus poemas debe necesariamente, cuando se trata de una novela, interrumpirse - en general más de una vez- aunque no sea 
sino en busca de una "tregua al ejercicio". Este criterio de distinción que en principio parece estar relacionado sólo con la extensión del texto narrativo tiene en realidad un origen más profundo y totalizador: un cuento es un relato programado para una conciencia que puede incorporarlo de una vez en su totalidad y en cada una de sus partes. Por lo tanto, visto desde la perspectiva de su composición, un cuento es una construcción continua, compacta, cuya solidez depende del ajuste y la tensión de todos sus elementos. El manejo de la tonalidad, las articulaciones de la prosodia, los efectos de la puntuación, el ángulo o la velocidad de la imagen, nada puede ser descuidado. Un cuento está trabajado en el nivel de la frase y aun de la palabra: cuando Horacio Quiroga sugiere, en su célebre Decálogo, que el buen cuentista antes de escribir la primera palabra de un cuento sabe ya cuál será la última está no sólo señalando la fuerte tensión de su estructura sino también que la paläbra (su contenido semántico pero también su peso, su sonoridad, su cantidad silábica) es la pieza compacta sobre la que aquella estructura se hace fuerte. Tanto como el ejecutor, el buen lector sabe que en un cuento todo ha de ser economía, rigor, que una nota que pudo haber sido omitida o que no se encuentra en su lugar es una nota falsa. Este sentido de la economía del conjunto, de la concentración intelectual y del control de las emociones es lo que preside la composición e igualmente la interpretación - la partitura y su ejecución, para recordar otra vez a Valéry- y por eso su límite no puede sobrepasar el de la atención perceptiva. A este respecto el cuento debe satisfacer las mismas exigencias que el poema y casi todo lo que Edgar A. Poe, en su Filosofia de la composición ha dicho de esta forma literaria (incluso, mutatis mutandi, lo que se refiere a la versificación) puede ser aplicado al cuento. Por lo demás, El cuervo - motivo de las reflexiones de Poe- es, como se sabe, un poema narrativo.

Superado este límite de la conciencia perceptiva, la estrategia de la composición y de la recepción del relato varía sensiblemente. Si un relato está programado para una lectura que puede interrumpirse sin vulnerarlo, sus unidades y sus técnicas de estructuración han de ser otras y sobre todo otra la imagen del lector. Entre una sesión de lectura y la que le sigue hay valores que se pierden y valores que pueden ser 
recuperados: sobre estos últimos --valores que suelen emerger de la historia más que del discurso- ha de hacerse fuerte la narración. Que la interrupción calculable sea una sola o sean varias es menos importante que el hecho mismo de que la interrupción entre en el cálculo. La diferencia que va de una "novela corta" a una "novela larga", pongamos por caso, por más grande que sea parece ser menos decisiva que la que va entre una "novela corta" y un "cuento". La novela tendrá siempre otra sintaxis y se ofrecerá a otra forma de apropiación. Una novela supone una estructura organizada sobre piezas relativamente más complejas, polimorfas ( $\mathrm{y}$ también polifónicas), en la que se reúnen unidades que hacia su interior son relativamente descomponibles y hacia su exterior relativamente desprendibles. En todos los casos estas unidades se sitúan más allá de la frase. Elementos complejos como personajes, situaciones, alternativas de la descripción y la narración, desplazamientos del punto de vista, juegos de los parágrafos y capítulos, modos y tiempos de la enunciación son, entre otros, las unidades de base cuya dispositio organiza el proceso narrativo. Por debajo de tales elementos, los rasgos menores que intervienen en su composición pueden estar menos atendidos sin que el efecto general se debilite sensiblemente. Las frases pueden no ser demasiado felices si su agnupación en secuencias narrativas o descriptivas alcanzan un efecto perdurable y convincente. De Roberto Artl y hasta de Cervantes pudo decirse que escribieron muchas frases defectuosas pero nadia afirmará que por eso Los siete locos o Don Quijote han perdido eficacia en algún punto esencial.

Por otra parte, mientras el cuento es una continua concentración de la tensión, la novela es más bien una distribución de la tensión en diferentes nudos de interés. Por lo tanto, en el intervalo que va de un nudo a otro la tensión no sólo puede sino a menudo debe distenderse pues el ritmo narrativo - que es también el ritmo de una tensión interior-consiste en un equilibrio de aceleraciones y de pausas. Estas diferencias de técnicas y estrategias narrativas pueden ser intuidas sin mayor dificultad, y un lector medianamente experimentado puede advertir, aun ante una sola página, si se trata de la página de un cuento o de la página de una novela. 
3. Si el cuento y la novela difieren, es por estar organizados sobre unidades de distinta magnitud y complejidad, por una diferente trabazón de su sintaxis y sobre todo por una diversa estrategia narrativa. Es éste un rasgo decisivo que, de paso, explica en gran parte su preponderancia como instituciones de nuestra cultura. Siempre que hablamos de cuento o de novela se sobreentiende que nos referimos al mundo de los libros, a la palabra escrita que circula entre destinadores y destinatarios "cultos". Sus claves, sus técnicas, sus convenciones pertenecen al orden de la escritura y son inimaginables fuera de ella. Desde esta perspectiva, la elección dei vocablo "cuento" para designar una de estas formas de escritura parece no ser afortunada ya que el mismo vocablo viene designando, desde un estadio cultural anterior, acontecimientos narrativos de la tradición oral: el "cuento", en esa tradición, es el producto del acto de "contar", acto que pone en relación de presencia a un hombre que habla y a otro(s) que escucha(n). Es necesario advertir esta distinción pues el "cuento", como lo venimos entendiendo en este trabajo, es exactamente lo contrario: no sólo arte de la escritura sino, cada vez más, una exigencia de virtuosismo que hace de él, acaso, el género más artificioso que cultivan los escritores de nuestros días. Los cuentos de Rulfo, por ejemplo, que tan bien evocan un mundo de comunicación oral, son sin embargo una muestra rigurosa de este arte de la escritura. Son cuentos imposibles de "contar" pues el contar supone la libertad de introducir variaciones circunstanciales cada vez que el acto comunicativo vuelve a realizarse mientras que un cuento de Rulfo ---medido sílaba a sílaba- no admite en su discurso la menor variación.

Y bien; los destinadores y destinatarios de la literatura que convencionalmente podemos llamar "culta" participan de una conciencia colectiva que identifica de inmediato las especies del cuento y la novela Sin embargo esa misma conciencia percibe también de inmediato - aunque de manera difusa- que el universo de los relatos literarios de ningún modo se acaba allí sino que, por el contrario, más allá de ambas especies se abre un vasto, ilimitado espacio en el que proliferan otras formas narrativas. Aún sin salimos del circuito trazado por los libros, pensemos en formas tales como crónicas, memorias, epistolarios, 
relaciones de viajes o aventuras, anecdotarios, testimonios, etc. Sobre una posible clasificación de esta variedad de relatos, sobre su retórica propia, sobre las convenciones de su composición y su lectura, poco seguro podemos decir porque la crítica se ha ocupado relativamente poco de su estudio, y nunca sistemáticamente. Precisamente es necesario insistir sobre la existencia de tales relatos para señalar esta falta, que es otra de las pobrezas de nuestra cultura literaria. De todos modos, como aproximación primaria y general, podríamos decir que esas formas, aunque escritas, parecen depender más de la voz que de la escritura. Mejor dicho: su estrategia parece ser la re-presentación del acto narrativo mediante técnicas que evocan la entonación y los hábitos de la voz Se trata de relatos de extensión siempre indeterminada y de estructura laxa, lo que hace naturalmente posible los agregados, las correcciones y las interpolaciones, los desplazamientos y los retardos, las interrupciones y desvíos. En ellos el interés suele no residir tanto en la necesidad de avanzar hacia un final cuya fuerza y coherencia legitimará el relato entero - lo que es el caso de la novela y sobre todo del cuento- cuanto en progresar tramo por tramo cubriendo un cierto recorrido narrativo entregados a una especie de deriva. Tales relatos son, pues, en sentido estricto, narraciones -0 , si se quiere, relaciones-; esto es: más bien actividad que resultado; actividad de una voz narrante que trata de convencernos de que la aventura consiste por lo menos tanto en el contar como en lo contado. Al interés por la peripecia de los personajes de la historia se le sumará entonces $-\mathrm{y}$ a veces se antepondrá- el interés por la peripecia de la propia narración, el ir y venir de la voz, el flujo de una enunciación cuyo tono sube o baja y cuyo ritmo vacila en busca de una palabra que nunca será la última. Según esa necesidad estratégica, tales relatos presentan el tipo de estructura a la que Amold Hauser -refiriéndose a ciertas narraciones épicas o caballerescas - dio el nombre de "aditiva": estructura abierta y destrabada, sucesión de episodios yuxtapuestos y articulados alrededor de una imagen central de tal modo que esa imagen se va componiendo sin un plan aparente, por la acción del recuerdo o del olvido. Ligados al cauce de la voz, estos relatos son también representación del flujo de la vida, del íntimo 
deseo de perdurar. También en este último aspecto, es importante señalarlo, tales relatos se alejan de las formas del cuento y la novela pues estos dos géneros son resultado de un trabajo artístico en el que la llegada hacia un punto finál gravita continuamente determinando la estructura; este punto final está en cierto modo concebido como principio del texto y sobre todo como dirección del deseo; así, casi no se encontrará lector dispuesto a comenzar la lectura de una novela sin tener, desde el principio, la garantía de que nada lo privará de ese final al que se ha encaminado sin descanso.

Pero no pasa así en estos relatos; aquí, por el contrario, el punto final está siempre diferido, resistido, pues estas narraciones, más que el deseo del fin, ilustran el deseo de la continuidad. Podríamos decir que el modelo de estas narraciones es el libro de Las mil y una noches, modelo por excelencia ya que ese libro nos pone ante una sucesión infinita de relatos y sobre todo ante las astucias de una voz cuya supervivencia depende de la posibilidad de crear la fascinación de lo continuo y --por ello mismo- de una política narrativa encaminada a diferir incesantemente el deseo del fin que - bien se ve aquí- es deseo de la muerte.

4. He escrito "podríamos decir" pues nuestra cultura ha incorporado las narraciones de Las mil y una noches a la experiencia del libro y de ese modo nos ha puesto frente a un discurso que no es actuación sino representación del incesante flüir de la voz. Sin embargo, como sabemos, Las mil y una noches, en el origen y en su cultura, es narración oral, contacto de boca a oído, voz azarosa que reproduce otra voz primordial, afirmación, en fin, de un devenir verbal siempre presente.

Si las narraciones a que hemos aludido son re-presentación de la voz, todavía nos queda por aludir al universo de la voz presente, esto es al dilatado ámbito de la oralidad. Los relatos, que provienen de este ámbito se organizan según técnicas constructivas y estilos de ejecución que preceden a las especializaciones discursivas que son propias de la escritura y nos instalan ante un murmullo en el que toma forma y por el que se propaga una cosmovisión completa, un sentido de la vida, es decir, una cultura. Si todavia los clasificamos como relatos literarios 
-por una convención cuya pertinencia no discutiremos aquí-- es porque son fruto de un trabajo artístico y porque, en todo caso, son el origen de una actividad simbólica que desembocaría en el libro. Que estas formas narrativas sean anteriores a la escritura no quiere decir necesariamente que todás sus muestras han sido compuestas hace mucho tiempo sino que cada relato pone en circulación procesos de intercambio o modos de socialidad cuyas leyes profundas son las que ordenan el arte de la comunicación verbal. Por esta razón, y asumiendo el punto de vista que como lectores "cultos" estamos obligados a asumir, la oralidad no será para nosotros tanto el conjunto de mensajes hablados y escuchados cuanto el conjunto de formas de la enunciación cuyos modelos de base o estructuras subyacentes provienen del ciclo primario de la transmisión oral y nos sitúan, en consecuencia, ante una experiencia lingüística según la cual el mensaje traza un movimiento que va del sonido al sentido, movimiento ritmado por la respiración y regulado por la memoria. Palabra o frase, entonación o pausa, el mensaje está hecho de una materia sonora de extensión temporal y, por ello mismo, su perdurabilidad depende de una combinatoria de regularidades - sonidos que retornan, formulas enunciativas que aparecen una y otra vez, periodizaciones de la sintaxis-y de variaciones que aseguran a la vez la conservación y la progresión del sentido: la experiencia oral, que tiende a salvar las palabras ritualizándolas con el recurso del versus es, dicho sea de paso, el origen de la poesía.

Ir a la búsqueda de la oralidad supone, hoy por hoy, un trabajo de reconstrucción pues, en la práctica, la oralidad está permeada por hábitos lingüísticos que provienen de là escritura. Las relaciones entre oralidad y escritura son múltiples e intrincadas no sólo porque la escritura tiene un prestigio - un poder- que la hace objeto de imitación sino sobre todo porque ésta tiende a absorber a aquélla. En el caso de los relatos, como en otras formas del mensaje verbal, las influencias recíprocas y las zonas de contacto son tan numerosas que es necesario, para un examen, articular los mensajes con la tradición que puede explicarlos. Globalmente, debemos concebir los relatos de tradición oral como un flujo de informaciones narrativas destinados a formar la memoria colectiva. Las técnicas de enunciación deben 
cumplir, para ello, la función de hacer perdurable lo que por naturaleza es efímero. Ya que la palabra está entregada a su precaria duración, destinada al olvido, y ya que al mismo tiempo la palabra, y sólo la palabra, es lo que funda el ser social, resulta necesario que el tiempo, más que transcurso, sea duración, retorno de lo mismo. Por ello el principio de estas narraciones suele ser la reiteración: sonoridades y fórmulas recurrentes, paralelismos sintácticos y semánticos, permutaciones binarias, circularidad de motivos, etc.

Por otra parte, dado que la fuente y el destino de tales relatos es la memoria colectiva, más que interrogar los relatos será necesario interrogar esa memoria o, dicho de otro modo, resulta necesario saber que un relato es siempre, al mismo tiempo que una expresion de formulas y motivos recurrentes, el motivo de un sistema en el cual toma forma la totalidad de una cultura. Si los relatos son muchas veces fragmentarios, incoherentes e incluso contradictorios, ello no debe desalentar los esfuerzos del estudioso sino-como aconsejaba Rilke a su joven poeta - enseñarle a conducir su mirada hacia lo profundo pues "en lo profundo todo se vuelve ley". El azar al que una cotidiana circulación los destina es compensado, en lo profundo, por una necesidad rigurosa. Allí las fórmulas, insistentes y entrecortadas, componen acaso un continuado rito.

Leyendas, mitologías, relaciones de sucesos extraordinarios y edificantes, adversidades o venturas del vivir, heridas del amor esquivo, tragedias, venganzas, fantasias del deseo, apariciones, sueños, la variedad de estos relatos es literalmente infinita y al mismo tiempo regulada por los procesos de la memoria, los mandatos de la lengua, y la ubicua gravedad de la cultura. Así, al interrogar este murmullo incesante y multiforme, el crítico ha de saber, desde luego, que aunque se interese por tales relatos como materia artística, inevitablemente trabajará en terrenos colindantes con la antropología. Ampliada de este modo su visión, el crítico tendrá ante sí el despliegue de toda una cultura y ello le planteará, ciertamente, problemas que no pueden resolverse sin el auxilio de métodos comparatistas. Tal cosa nada tiene de sorprendente pues toda investigación en literatura tiende a recurrir al comparatismo en la medida en que nunca se conoce una forma o una 
obra sino poniéndola en relación de contraste o semejanza con otra que, precisamente por ser otra, ayudará a explicar la primera. Esta afirmación que tiene una validez general cobra particular relieve cuando se trata del universo de la oralidad donde, a favor de la azarosa circulación de la palabra viva, se opera una suerte de dispersión que debe ser reducida por obra de un paciente cotejo de las piezas.

5. En suma: con estas líneas hemos apenas sugerido una posibilidad de orientarnos en la vastedad del universo de los relatos. Con facilidad se advierte que conocer y clasificar esa dilatada materia desde un punto de vista literario plantea problemas que están muy lejos de ser fáciles. Esa dificultad, sin embargo, no puede impedimos razonar que mientras no tengamos una visión aceptable de la totalidad tampoco la parte alcanzará a ser conocida de un modo aceptable para la inteligencia. En cuanto ponemos en relación la parcela a la que el crítico suele dedicarse con todo el -intuible--universo de los mensajes en los que la palabra adquiere forma artística, nuestra concepción de la literatura revela su insuficiencia. La literatura es eso que todavía no alcanzamos a ver. En el caso de los relatos, ellos continúan su proliferación más allá de los géneros que nuestros hábitos han institucionalizado. Tal vez el esquema ternario que aquí hemos bosquejado, pueda en el inicio ayudarnos a distribuir esa proliferación sobre un cuadro de coherencias. Se trata de un esquema que atiende básicamente al medio en que los relatos se producen pero este medio puede informarnos acerca de sus formas de ejecución y sus circuitos de intercambio puesto que en gran medida los determina. En este sentido, comenzar - como tratamos de hacerordenando los relatos según sean acontecimientos de la escritura 0 , en el otro extremo, de la oralidad o, en la transición, formas representativas de la voz (formas en que la escritura y la oralidad encuentran una móvil convergencia) es sólo un paso primario pero quizá consistente y comprensivo. Al mismo tiempo, este principio clasificatorio no contradice nuestra conciencia actual, siempre pronta a hacerse fuerte en la identificación de muestras del repertorio de la cuentística o de la novelística. La clasificación de estas dos especies de relato literario queda de tal modo preservada - como es inevitable, pues se trata de un hecho colectivo- pero su preponderancia y sobre todo su peso 
institucional se relativiza. Reconociendo esa relatividad, nuestro conocimiento adquiere de hecho más riqueza. Tendemos a confundir una - seguramente pequeña-provincia con el mapa entero. Pero el conocimiento es aquel empeño de la inteligencia que termina por mostramos, a cada paso, que lo que no conocemos continuamente crece. 